\title{
OPTIMIZATION AND COMPARISON OF DIFFERENT STANDARDS FOR COMPRESSED WELDED BOX COLUMNS
}

\author{
${ }^{1}$ Károly JÁRMAI ${ }^{*}$ Máté PETRIK \\ ${ }^{1,2}$ Institute of Energy and Chemical Machinery, Faculty of Mechanical Engineering and \\ Informatics, University of Miskolc, H-3515 Miskolc, Hungary \\ e-mail: ${ }^{1}$ jarmai@uni-miskolc.hu, ${ }^{2}$ vegypet@uni-miskolc.hu
}

Received 10 January 2019; accepted 18 September 2019

\begin{abstract}
Stability is one of the most critical problems in the design of welded metal structures, since in many cases instability causes failure or collapse of the structures. The present study aims to show the minimum mass design procedure for welded steel box columns loaded by a compression force. The normal stresses and overall stability are calculated for pinned columns. The dimensions of the box columns are optimized by using constraints on global stability, local buckling of webs and flanges. Different design rules and standards are compared: Eurocode 3, Japan Railroad Association, American Petroleum Institute, and American Institute of Steel Construction. The calculations are made for different loadings, column length and steel grades. The yield stress varies between 235 and $690 \mathrm{MPa}$. Optimization is carried out using the generalized reduced gradient method in Excel solver. Cost calculations and comparisons show the most economical structure.
\end{abstract}

Keywords: Welded column, Structural optimization, Overall stability, Minimum mass

\section{Introduction}

The view of the literature shows the complexity of the problem, how to handle the overall and local buckling at compressed struts and the differences between the solutions and design rules.

The development in the calculation of overall buckling of compressed struts shows clearly how the model was refined considering the fabrication aspects. In the first phase, Euler [1] has solved the differential equation for a vertical strut to obtain the critical

${ }^{*}$ Corresponding Author 
force. In the second phase, Ayrton and Perry [2] considered the initial crookedness as regards the initial imperfections (Faulkner [3], Ellinas et al. [4]). It is worth describing their model, since this model is the basis of the Eurocode 3 [5] overall buckling formula.

In the third phase, the effect of residual welding stresses was considered. The European overall buckling curves were determined for various welded sections based on statistical evaluation of many test results (Beer and Schulz [6]). The tests showed that the residual welding stresses significantly influence the buckling strength, mainly in the case of welded I-section, since compressive residual stresses occur at the edges of the flanges, decreasing the buckling strength (Farkas [7]) (Fig. 1).

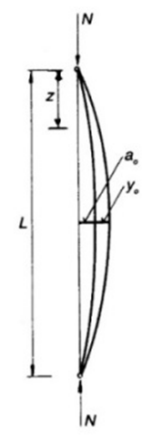

Fig. 1. The Ayrton-Perry model for initially curved column and the second order elastic deformation

\section{Compression members, flexural buckling}

Eurocode 3 (EC3) applies the formula proposed by Maquoi and Rondal [8]. This formula can be derived from Eq. (6) considering one parameter, which expresses the effect of initial imperfection and residual welding stresses as follows. The overall buckling formula can be derived based on checking the eccentric compression

$$
\frac{N}{A}+\frac{N\left(a_{0}+y_{0}\right)}{W_{x}} \leq f_{y}
$$

with notations of $\sigma=N / A, \sigma_{E}=F_{E} / A, \eta_{b}=a_{0} A / W_{x}$. Eq. (1) can be written in the form of

$$
\left(f_{y}-\sigma\right)\left(\sigma_{E}-\sigma\right)=\eta_{b} \sigma \sigma_{E} .
$$

This equation can be transformed using the following relationships

$$
\begin{array}{lc}
\sigma / f_{y}=\chi, & \sigma_{E} / f_{y}=\pi^{2} E /\left(f_{y} \lambda^{2}\right)=1 / \bar{\lambda}^{2}, \\
\bar{\lambda}=\lambda / \lambda_{E}, & \lambda_{E}=\pi \sqrt{E / f_{y}},
\end{array}
$$

to obtain

$$
(1-\chi)\left(\frac{1}{\bar{\lambda}^{2}}-\chi\right)=\frac{\chi \eta_{b}}{\bar{\lambda}^{2}}
$$


This leads to the following quadratic equation

$$
\chi^{2}-\left(1+\frac{\eta_{b}}{\bar{\lambda}^{2}}+\frac{1}{\bar{\lambda}^{2}}\right) \chi+\frac{1}{\bar{\lambda}^{2}}=0
$$

The solution of Eq. (5) is

$$
\chi=\frac{\varphi-\sqrt{\varphi^{2}-\bar{\lambda}^{2}}}{\bar{\lambda}^{2}}=\frac{1}{\varphi+\sqrt{\varphi^{2}-\bar{\lambda}^{2}}},
$$

where $\varphi=0.5\left(1+\eta_{b}+\bar{\lambda}^{2}\right)$ and $\eta_{b}=\alpha(\bar{\lambda}-0.2)$. For $\bar{\lambda} \leq 0.2$ it is $\chi=1$. $\alpha$ is the imperfection factor given for various buckling curves. The strut should be checked for

$$
N \leq \chi A f_{y} / \gamma_{M 1},
$$

where $\gamma_{M 1}=1.1$ is the safety factor for buckling.

It should be mentioned that the EC3 formula is too complicated for design (noncomputerized optimization) purposes. There exist other column curves used in other countries, which can be applied instead of EC3 curves. Fig. 2 shows some other buckling curves in addition to the EC3 curve ' $b$ '. The curve of the Japan Railroad Association (JRA) [9] gives values near the EC3 curve ' $b$ '. The following formulae describe the JRA curve:

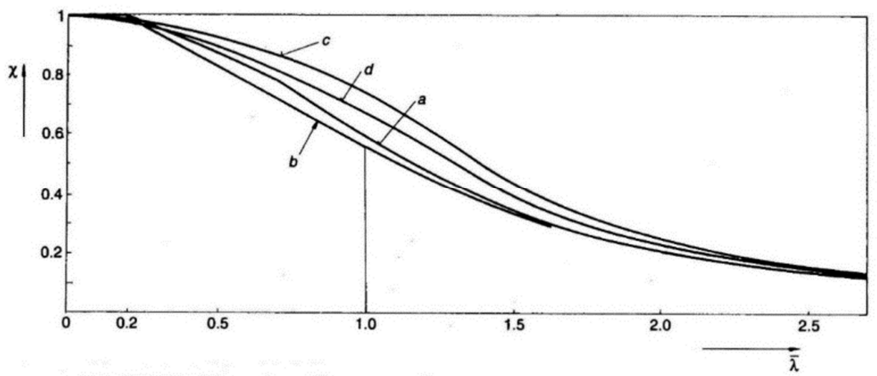

Fig. 2. Overall buckling curves according to a) EC3; b) JRA; c) API; d) AISC

$$
\begin{array}{ccc}
\chi=1, & \text { for } & \bar{\lambda} \leq 0.2, \\
\chi=1.109-0.545 \bar{\lambda}, & \text { for } & 0.2 \leq \bar{\lambda} \leq 1 \\
\chi=1 /\left(0.773+\bar{\lambda}^{2}\right), & \text { for } & \bar{\lambda} \geq 1 .
\end{array}
$$

The curve of the American Petroleum Institute (API) [10] is defined by

$$
\begin{array}{ccc}
\chi=1-0.25 \bar{\lambda}^{2}, & \text { for } & 0 \leq \bar{\lambda} \leq 1.41, \\
\chi=1 / \bar{\lambda}^{2}, & \text { for } & \bar{\lambda} \geq 1.41 .
\end{array}
$$

The curve of the American Institute of Steel Construction (AISC) [11] mainly for round tubes is given by

$$
\begin{gathered}
\chi=1-0.091 \bar{\lambda}-0.22 \bar{\lambda}^{2}, \quad \text { for } \bar{\lambda} \leq 1.41, \\
\chi=0.015+0.834 / \bar{\lambda}^{2}, \quad \text { for } \bar{\lambda} \geq 1.41 .
\end{gathered}
$$


In the fourth phase the experiments carried out on thin-walled rectangular hollow section compression struts that at the University of Liege have shown the interaction of local buckling of plate elements and the overall buckling. When the plate element buckles, which is loaded by maximum compressive stress, the overall buckling strength decreases? Braham et al. [12] have proposed a reduction factor in this case, which is included in EC3 as follows: Eq. (7) is modified to

$$
N \leq \beta_{A} \chi A f_{y} / \gamma_{M 1}, \quad \text { and } \bar{\lambda}=\lambda \sqrt{\beta_{A}} / \lambda_{E},
$$

where $\beta_{A}=1$ for cross-sections of class 1,2 and $3, \beta_{A}=A_{\text {eff }} / A$ for class 4 crosssections. The area of the effective cross-section $A_{\text {eff }}$ can be calculated using the effective width formulae for compression elements.

In summary, it can be concluded that the development of the strength calculation leads from Euler's differential equation to the EC3 formulae, which take into account the initial imperfections, residual welding stresses and the interaction of local and overall buckling. Note that the interaction of two instability phenomena plays a vital role in the optimum design.

The effective length factor $K$ expresses the effect of end restraints. The traditional values are $K=1$ for pined-pined, $K=2$ for fixed-free, $K=0.5$ for fixed-fixed ends. Different values are used in frame and truss analysis.

\subsection{Limiting plate slenderness}

It is useful for designers to define limiting plate slenderness, since in this case it is not necessary to calculate with effective widths and the cross-section can be categorized in class 3. In the optimum design the local buckling constraints can be expressed employing the limiting plate slenderness. For the definition the basic formula of Eq. (12) can be used:

$$
\sigma_{c r}=k_{\sigma} \frac{\pi^{2} E}{12\left(1-v^{2}\right)}\left(\frac{t}{b}\right)^{2} \geq \sigma_{\max }
$$

where $\sigma_{\max }$ is the design stress, usually the yield stress, but in the case when the deflection or the fatigue constraint is active, the actual maximum static or fatigue stress can be used. From Eq. (12) the following limiting slenderness can be calculated

$$
\left(\frac{b}{t}\right)_{L}=\sqrt{\frac{k_{\sigma} \pi^{2} E}{12\left(1-v^{2}\right) \sigma_{\max }}}
$$

In EC3 the stress of $235 \mathrm{MPa}$ is selected for basis and the ratio of $\varepsilon=\sqrt{235 / f_{y}}$ is introduced. With values $E=2.1 \cdot 10^{5} \mathrm{MPa}$ and $v=0.3 \mathrm{Eq}$. (13) takes the form of

$$
\left(\frac{b}{t}\right)_{L}=28.42 \varepsilon \sqrt{k_{\sigma}} \sqrt{\frac{f_{y}}{\sigma_{\max }}} .
$$

For a simply supported uniformly compressed plate (e.g. a flange of a box girder) $k_{\sigma}=4.0$ and

$$
(b / t)_{L}=56.84 \varepsilon \sqrt{f_{y} / \sigma_{\max }}
$$


Since this value does not contain the effect of initial imperfections and residual welding stresses, EC3 gives instead of 56.84 the value of 42, which is the ration of the plate with and thickness.

For a uniformly compressed plate with three edges simply supported and the fourth free (e.g. half width of flanges of a welded I-section) with $k_{\sigma}=0.456$,

$$
(b / 2 t)_{L}=19.19 \varepsilon \text {, in EC3 } 14 \varepsilon \text {. }
$$

For a simply supported plate loaded in bending (web of a doubly symmetric welded I-beam) $k_{\sigma}=23.9$,

$$
\left(h / t_{w}\right)_{L}=138.94 \varepsilon, \quad \text { in EC3 }\left(h / t_{w}\right)_{L}=124 \varepsilon .
$$

\section{Optimization}

Requirements for modern load-carrying structures are the safety, fitness for production and economy. In the optimum design procedure the safety and fitness for production are guaranteed by fulfilling design and fabrication constraints, and the economy is achieved by minimization of the mass, or the cost function.

\subsection{Objective function}

The objective function to be minimized selected for this study is the mass and the cost of the box column (Fig. 3). The cost function of a real structure may include the cost of material, assembly, the different fabrication costs like welding, surface preparation, painting and cutting, edge grinding, forming the geometry, etc. In this case, welding and painting costs have been considered.

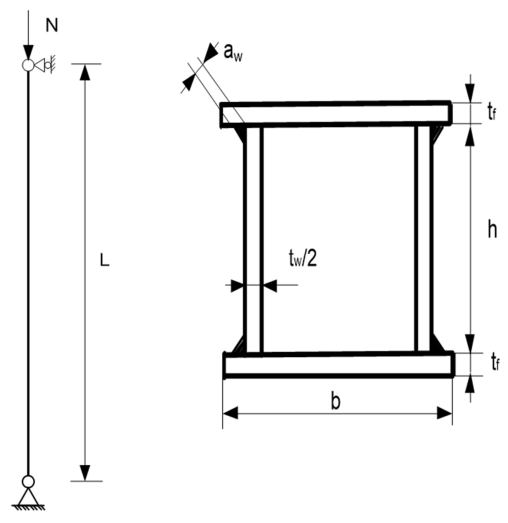

Fig. 3. The welded box column

The cost of materials

The material cost is defined as 


$$
K_{M}=k_{M} \rho V,
$$

where $K_{M}[\mathrm{~kg}]$ is the fabrication cost; $k_{M}[\$ / \mathrm{kg}]$ is the corresponding material cost factor; $V\left[\mathrm{~mm}^{3}\right]$ is the volume of the structure, $\rho$ is the density of the material. For steel it is $7.85 \cdot 10^{-6} \mathrm{~kg} / \mathrm{mm}^{3}$, for aluminum $2.7 \cdot 10^{-6} \mathrm{~kg} / \mathrm{mm}^{3}$, for stainless steel $7.78 \cdot 10^{-6} \mathrm{~kg} / \mathrm{mm}^{3}$. If several different materials are used, then it is possible to use different material cost factors simultaneously in Eq. (18). For steel the specific material cost can be $k_{M}=1.0-1.3 \$ / \mathrm{kg}$ depending on the thickness.

\section{The fabrication cost in general}

The fabrication cost is defined as

$$
K_{f}=k_{f} \sum_{i} T_{i},
$$

where $K_{f}[\$]$ is the fabrication cost, $k_{f}[\$ / \mathrm{min}]$ is the corresponding fabrication cost factor, $T_{i}$ [min] are production times. It is assumed that the value of $k_{f}$ is constant for a given manufacturer.

\section{Fabrication times for welding}

The main times related to welding are as follows: preparation, assembly, tacking, time of welding, changing the electrode, deslagging and chipping.

\section{Calculation of the times of preparation, assembly and tacking}

The times of preparation, assembly and tacking can be calculated with an approximation formula as follows

$$
T_{w 1}=C_{1} \Theta_{d w} \sqrt{\kappa \rho V},
$$

where $C_{1}$ is a parameter depending on the welding technology (usually equal to 1 ); $\Theta_{d w}$ is a difficulty factor; $\kappa$ is the number of structural elements to be assembled. The difficulty factor expresses the complexity of the structure. Difficulty factor values depend on the kind of structure (planar, spatial), the kind of members (flat, tubular). The range of values proposed is between 1-4 (Farkas, Jármai [13]).

\section{Calculation of real welding time}

Real welding time can be calculated as

$$
T_{w 2}=\sum_{i} C_{2 i} a_{w i}^{2} L_{w i},
$$

where $a_{w i}$ is weld size; $L_{w i}$ is weld length; $C_{2 i}$ is constant for different welding technologies. $C_{2}$ contains not only the differences between welding technologies, but the time differences between positional (vertical, overhead) and standard welding in down-hand position as well. The equations for different welding technologies can be found in Farkas, Jármai [13]. 


\section{Calculation of additional fabrication actions time}

There are some additional fabrication actions to be considered such as changing the electrode, deslagging and chipping. The approximation of this time is as follows [13]:

$$
T_{w 3}=0.3 \sum_{i} C_{2 i} a_{w i}^{2} L_{w i} \text {. }
$$

In is proportional to $T_{w 2}$. It is approximately $30 \%$ of it. The two-time elements are as follows:

$$
T_{w 2}+T_{w 3}=1.3 \sum_{i} C_{2 i} a_{w i}^{n} L_{w i} .
$$

\section{Fabrication times for painting}

The painting means making the ground- and the topcoat. The painting time can be given as a function of the surface area $\left(A_{s}\left[\mathrm{~mm}^{2}\right]\right)$ as follows:

$$
T_{C P}=\Theta_{d p}\left(a_{g c}+a_{t c}\right) A_{s},
$$

where $a_{g c}=3 \cdot 10^{-6} \mathrm{~min} / \mathrm{mm}^{2} ; a_{t c}=4.15 \cdot 10^{-6} \mathrm{~min} / \mathrm{mm}^{2} ; \Theta_{d p}$ is a difficulty factor, $\Theta_{d p}=1,2$ or 3 for horizontal, vertical or overhead painting, respectively. Tizani et al. [14] proposed a value for painting of $14.4 \cdot 10^{-6} \$ / \mathrm{mm}^{2}$. For more complicated structures we use $k_{P}=2 \cdot 14.4 \cdot 10^{-6} \$ / \mathrm{mm}^{2}$. In this case $T_{C P}=k_{P} \cdot A_{s}$. The cross-sectional area is as follows

$$
A=2 h t_{w} / 2+2 b t_{f} .
$$

The total cost function can be formulated by adding the previous cost functions together

$$
\frac{K}{k_{m}}=\rho V+\frac{k_{f}}{k_{m}}\left(T_{w 1}+T_{w 2}+T_{w 3}+T_{C P}\right) .
$$

Taking $k_{m}=0.5-1.5 \$ / \mathrm{kg}, k_{f}=0-1 \$ / \mathrm{min}$. The $k_{f} / k_{m}$ ratio varies between $0-2 \mathrm{~kg} / \mathrm{min}$. If $k_{f} / k_{m}=0$, then the minimum mass can be achieved. If $k_{f} / k_{m}=2.0$ it means a very high labor cost (Japan, USA), $k_{f} / k_{m}=1.5$ and 1.0 means a West European labor cost, $k_{f} / k_{m}=0.5$ means the labor cost of developing countries. Even if the production rate is similar to these cases, the difference between costs due to the different labor costs is significant. In the cost calculations the manual Shielded Metal Arc Welding (SMAW) and the normal speed Acetylene cutting technology have been used.

\subsection{Constraints}

The constraint of overall buckling is according to the standard, or design guide

$$
N \leq \chi A f_{y} / \gamma_{M 1}
$$

For the buckling parameter, see Eqs. (6)-(10). 
Constraint on local buckling of the web for the box column

$\frac{h}{t_{w} / 2} \leq \frac{1}{\beta}, \quad$ or $\quad t_{w} \geq 2 \beta$,

where

$1 / \beta=42 \varepsilon, \quad \varepsilon=\sqrt{235 / f_{y}}$.

The constraint for local buckling of the compressed upper flange of the box

$\frac{b}{t_{f}} \leq \frac{1}{\delta}=42 \varepsilon, \quad$ or $\quad t_{f} \geq \delta b$.

The constraint for local buckling of the compressed upper flange of I-column

$\frac{b}{t_{f}} \leq \frac{1}{\delta}=28 \varepsilon, \quad$ or $\quad t_{f} \geq \delta b$.

The stability plays an essential role in the design of steel structures [15], and neglecting this can cause the collapse of the structure.

\subsection{Unknowns to be optimized}

The sizes of the box cross-section $h, t_{w} / 2, b, t_{f}$.

There are lower and upper limits for the unknowns. The minimum thickness is $5 \mathrm{~mm}$, the maximum is $20 \mathrm{~mm}$. The minimum height and width are $80 \mathrm{~mm}$, the maximum is $350 \mathrm{~mm}$. The height is greater or equal to the width.

\subsection{Optimum design procedure}

There are several optimization methods available, like genetic algorithm [16]. In the Microsoft Excel Solver, the Generalized Reduced Gradient (GRG2) algorithm can be used for optimization in case of non-linear problems. The algorithm was developed by Leon Lasdon et al. (University of Texas at Austin) [17]. The algorithm avoids the use of penalty parameters by searching along curves that stay near the feasible set. Essentially, this method uses the equality constraints to eliminate a subset of the variables, thereby reducing the original problem to a bound-constrained problem in the space of the remaining variables. The method is searching for the solution with the expansion of the Taylor series with non-linear criteria. The effective method searches the unconditional Non-Linear Programming (NLP) problems with approximation. The process is repeated until the optimization criterion is fulfilled [17]. In some cases, the GRG2 method is not reliable. Comparisons of results have been made using the Evolutionary Solving Method. There were differences only in decimal places.

\subsection{Design data}

Compression force range $N=20-150[\mathrm{kN}]$; column length range $L=2-10$ [m]; yield stress range $f_{\mathrm{y}}=235,355,460,690[\mathrm{MPa}]$. 
Design rules: EC3=Eurocode 3, JRA=Japan Road Association, API=American Petroleum Institute, AISC=American Institute for Steel Construction.

\subsection{Optimum results, comparisons for the welded box column}

The optimization is performed for the box column. Changing the compression force, the yield stress and the length in the given ranges the behavior of the welded box beam can be evaluated.

Fig. 4 shows the optimum cross-sectional areas $\left[\mathrm{mm}^{2}\right]$ in the function of the compression force $[\mathrm{N}]$ for the welded box column: $K=0.7 ; L=4 \mathrm{~m} ; f_{\mathrm{y}}=460 \mathrm{MPa}$; loading is changing.

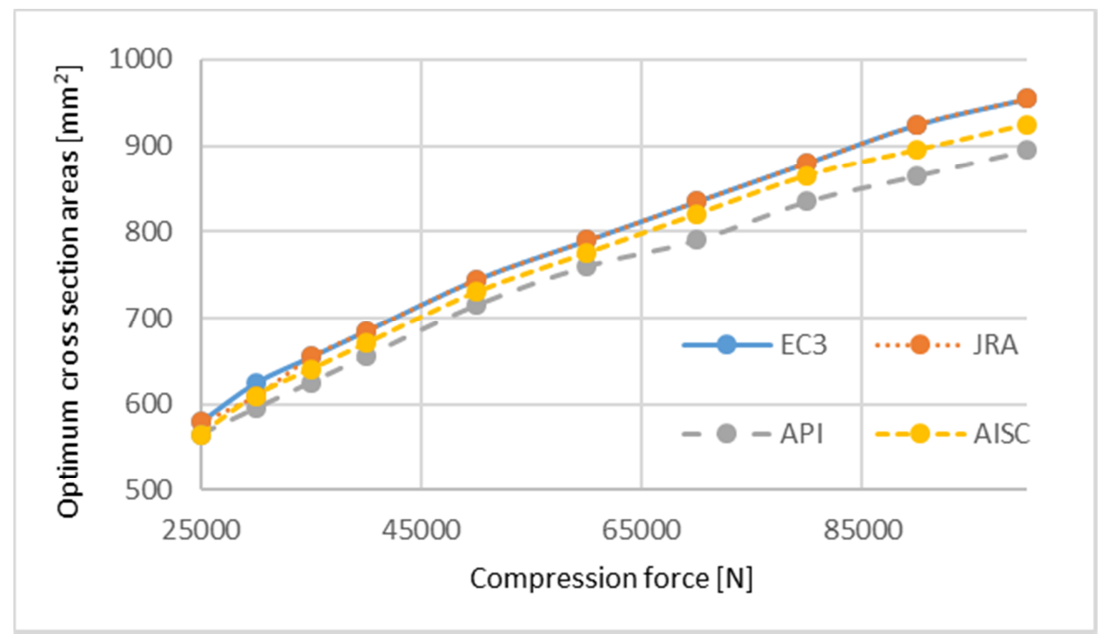

Fig. 4. Optimum cross-sectional areas as a function of the compression force, $L=4 \mathrm{~m} ; f_{\mathrm{y}}=460 \mathrm{MPa}$

Fig. 4 shows that there are differences in the optimum cross-sectional areas, using different design rules, or compression forces. The increment of the cross-sectional area is not linearly proportional to the compression force, but less. Most cases JRA requires the largest optimum cross-sectional area and the API needs the smallest one. It means that the JRA is stricter and the others are less.

Fig. 5 shows the optimum cross-sectional areas as a function of yield stress for the welded box column: $K=0.7 ; L=10 \mathrm{~m} ; N=1500000 \mathrm{~N}$. It shows that using better steel (higher yield stress) the optimum cross-sectional areas are decreasing up to 355 or $460 \mathrm{MPa}$, depending on the design rule, but later all increase. Considering the increasing material costs of high strength steels, the $355 \mathrm{MPa}$ yield strength steel is shown to be the best choice.

The differences in the cross-sectional areas are calculated as a function of the length, the steel grades and the design rules when the compression force is $N=85 \mathrm{kN}$ (Fig. 6). The value is calculated considering the cross-sections for the largest and the smallest steel grade and the percentage of the difference when the compression force is given to 
be $85 \mathrm{kN}\left(A_{\mathrm{S} 690}-A_{\mathrm{S} 235}\right) \cdot 100 \%$. Fig. 7 shows the different costs in the same cases, but in that case, the costs are compared $\left(C_{\mathrm{S} 690}-C_{\mathrm{S} 235}\right) \cdot 100 \%$.

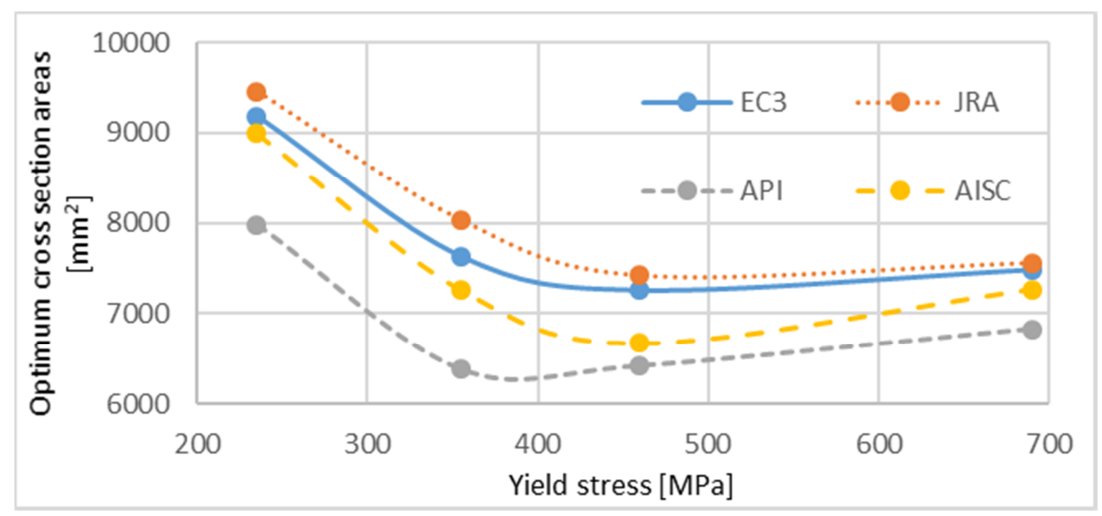

Fig. 5. Optimum cross-sectional areas as a function of the yield stress for box column, $L=10 \mathrm{~m} ; N=150 \mathrm{kN}$

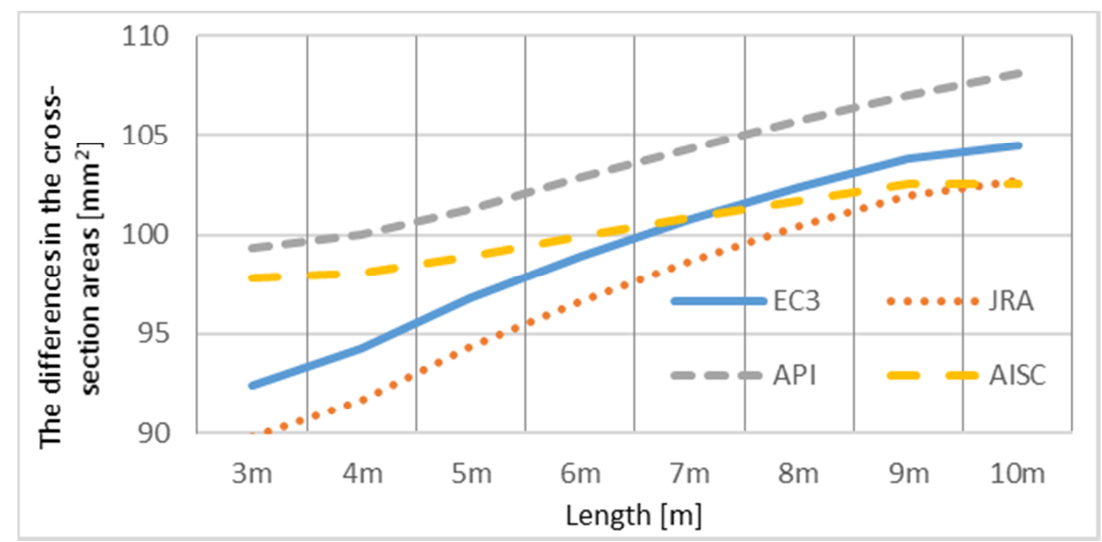

Fig. 6. The differences in the cross-sectional areas as a function of the length and design rules when the compression force is $N=85 \mathrm{kN}$

Fig. 6 shows that the most considerable difference in the cross-sectional area (mass) occurs using JRA and the smallest using AISC.

Fig. 7 shows the differences in the cost as a function of the compression force and design rules when the length is $L=10 \mathrm{~m}$. The optimum cost maximum and minimum steel grades $\left(C_{\mathrm{S} 690}-C_{\mathrm{S} 235}\right) \cdot 100 \%$. It shows that the enormous difference is at the AISC rules; the smallest difference is at the JRA. It should be mentioned that these differences are not too high, but it is interesting that the changes in the differences are high at low compression forces and later very similar. It means that it has no aim to use higher strength steels at small compression forces. To improve the optimization and to extend the calculation to fatigue behavior also, further considerations and constraints need to be 
considered. Post welding treatment is another technology to enhance the response of the joint, but mostly for dynamic loading.

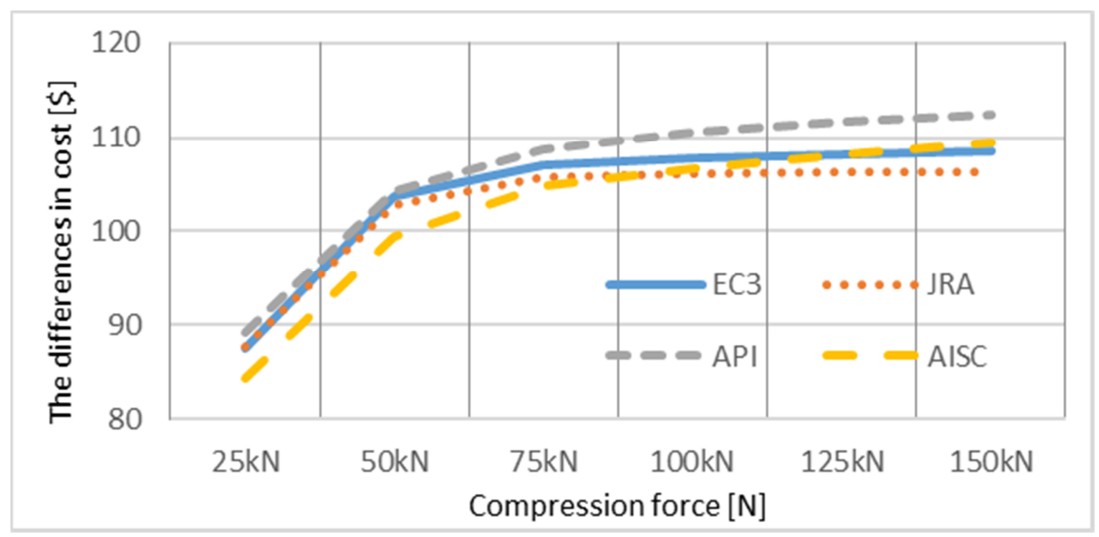

Fig. 7. The differences in costs as a function of the compression force and design rules, when the length is $L=10 \mathrm{~m}$

\section{Conclusions}

In the optimization process the height, the width and the thickness of the web and flanges have been optimized for the welded box beams. The objective function to be minimized was the cross-section (the mass) and the cost (including material, welding and painting), the constraints were the overall column buckling and local buckling of the web and flanges. The calculations show that for a predesign the optimization is applicable and very useful. The solver gives the result quickly. Building the optimization system in the solver environment is relatively easy for the user. Using different standards and design rules the optimum sizes and cross-sections are different. The JRA and EC3 look more conservative, the API is more liberal and the AISC is between them.

Changing the length and the compression force at the column, the cross-section (the mass of the column) is not linearly but less proportional to them. The reason is probably that the local buckling does not depend on them.

The yield stress has a unique effect. Increasing the yield stress from $235 \mathrm{MPa}$ up to $690 \mathrm{MPa}$, first, the cross-sections decrease at $355 \mathrm{MPa}$ but later increase. The reason is also at the local buckling constraint and even at the overall buckling one, because of the value of $\varepsilon=\sqrt{235 / f_{y}}$. Considering the cost of steel, it was found that the best is the $355 \mathrm{MPa}$ steel. Calculations show that it has no aim to use higher strength steels at low compression forces. At the calculations changing the column length, the compression force, the steel grade and the design rule shows that there is a complex behavior of the structure and it is worth to evaluate and compare the alternatives. 


\section{Open Access statement}

This is an open-access article distributed under the terms of the Creative Commons Attribution 4.0 International License (https://creativecommons.org/licenses/by/4.0/), which permits unrestricted use, distribution, and reproduction in any medium, provided the original author and source are credited, a link to the CC License is provided, and changes - if any - are indicated. (SID_1)

\section{References}

[1] Euler L. Determination of the loads, which are strong enough to bear the pillars, (in Latin) Acta Acad. Sci. Petrop, Vol. 2, 1776.

[2] Ayrton W. E., Perry J. On struts, The Engineer, Vol. 62, 1886, pp. 464-465, pp. 513-514.

[3] Faulkner D., Adamczak J. C. Snyder G. J., Vetter M. F. Synthesis of welded grillages to withstand compression and normal loads, Computers and Struct, Vol. 3, No. 2, 1973, pp. 221-246.

[4] Ellinas C. P., Supple W. J., Walker A. C. Buckling of offshore structures, Granada, London, 1984.

[5] Eurocode 3, Part 1.1, Design of steel structures, General rules and rules for buildings, European Committee for Standardization, Brussels, 1992.

[6] Beer H., Schulz G. Theoretical bases of European buckling curves, (in French) Construction Métallique, Vol. 3, No. 3, 1970, pp. 37-55.

[7] Farkas J. The effect of residual welding stresses on the buckling strength of compressed plates, Proc. Regional Colloquium on Stability of Steel Structures, Budapest, Hungary, 1921, September 1977, pp. 299-306.

[8] Maquoi R., Rondal J. Equation of the new European buckling curves, (in French) Construction Métallique, Vol. 15, No. 1, 1978, pp. 17-30..

[9] Specifications for Highway Bridges, Part I-V, Japan Road Association, JRA, 2012.

[10] Design of flat plate structures, Bulletin 2V, Third Ed., American Petroleum Institute, API, 2004.

[11] Stability design of steel buildings, Design guide 28, American Institute of Steel Construction, AISC, 2005.

[12] Braham M., Grimault J.P., Massonnet C., Mouty J. Rondal J. Buckling of thin-walled hollow sections, Cases of axially-loaded rectangular sections, Acier-Stahl-Steel, Vol. 45, 1980, pp. 30-36.

[13] Farkas J., Jármai K. Optimum design of steel structures, Springer, 2013.

[14] Tizani W. M. K., Yusuf K. O., Davies G., Smith N. J. A knowledge based system to support joint fabrication decision making at the design stage - Case studies for CHS trusses, VII. Proc. of the Seventh International Symposium on Tubular Structures, Miskolc, Hungary, 28-30 August 1996, Farkas J., Jármai K. (Eds), Rotterdam, Balkema, pp. 483-489.

[15] Iványi M. Ductility of steel structures: The model of interactive hinge, Pollack Periodica, Vol. 1, No. 1, 2006, pp. 5-34.

[16] Kota L., Jármai K. Efficient algorithms for optimization of objects and systems, Pollack Periodica, Vol. 9, No. 1, 2014, pp. 121-132.

[17] Lasdon L. S., Fox R. L., Ratner M. W. Nonlinear optimization using the generalized reduced gradient method, Operations Research, Vol. 8, No. V3, 1974, pp. 73-103. 